\title{
PENGARUH BRAND IMAGE DAN SERVICE QUALITY TERHADAP PURCAHSE INTENTION
}

\author{
Ilman Prasetyo \\ Program Studi Magister Manajemen Universitas Tarumanagara \\ prasetyoilman11@gmail.com
}

Masuk : 30-05-2020, revisi : 25-06-2020 diterima untuk diterbitkan : 26-06-2020

\begin{abstract}
The aim of this study are: First, to explore the effect of brand image on purchase intntion. Second, to explore the effect of service quality on purchase intention. The method of data collection is convenience sampling. The samples of this research are collected from 150 respondens, who are the customers of Coffee shop in Jakarta. The technique of data analysis used in this study was multiple regression analysis and classic assumption test. Testing the result of Hypoteses used the F-test, t-test, and $\mathrm{R}^{2}$. The results are: (a) the effect between brand image have a significant and positive impact toward purchase intention; (b) the effect between service quality have a significant and positive impact toward purchase intention
\end{abstract}

Abstrak : Tujuan dari penelitian ini adalah : pertama, untuk menguji efek dari brand image terhadap minat beli. Kedua, untuk menguji efek dari kualitas pelayanan terhadap minat beli. Metode dari pengambilan data adalah convenience sampling. Sampel merupakan pelanggan kedai kopi di Jakarta. Sampel dari penelitian ini adalah 150 responden. Teknik dari data analisis penelitian ini adalah analisis regresi berganda dan Uji asumsi klasik. Pengujian hasil hipotesis menggunakan Uji-F, Uji-t, dan $\mathrm{R}^{2}$. Hasilnya adalah : Hasilnya adalah (a) brand image mempunyai pengaruh positif terhadap purchase intention. (b) service quality mempunyai pengaruh positif terhadap purchase intention.

Keywords : Brand Image, Service Quality, Purchase Intention

\section{PENDAHULUAN}

Seiring berjalannya waktu, perubahan zaman dapat mengubah gaya hidup seseorang sehingga dapat menyebabkan ramainya kompetisi dalam sebuah produk atau jasa yang akan diminati oleh pasar. Setiap perusahaan harus mempunyai keinginan untuk berkembang atau minimal bertahan hidup dengan memberikan produk atau jasa yang lebih unggul dari pesaingnya.

Dalam industri jasa seperti kedai kopi, persaingan yang terjadi semakin ketat. Saat ini pertumbuhan usaha kedai kopi di Indonesia sangat pesat. Kedai kopi lokal secara sporadis mengisi persaingan industri kedai kopi, seperti: kopi tuku, 31 coffee shop, janji jiwa, kopi tanamera, dan lain sebagainya. Dengan adanya persaingan ini, menyebabkan pilihan konsumen akan menjadi beragam. Keberagaman ini membuat pengusaha kedai kopi saling menunjukkan ciri dari masing-masing kedai kopi, dampaknya adalah setiap kedai kopi memiliki pelanggan yang terus kembali ke kedai kopi tersebut. Hal itu membuat setiap kedai kopi harus memiliki keunggulan kompetetif sebagai salah satu kunci sukses bagi suatu perusahaan, yang salah satunya dalam industri jasa yang harus dimiliki sebuah perusahaan jasa adalah menyediakan layanan jasa yang berkualitas dan juga fasilitas yang lengkap.

Minat beli pelanggan adalah target utama keberhasilan sebuah usaha karena menjadi sumber dari pemasukan perusahaan, berkaitan dengan hal itu menurut Oosthuizen (2015) menjelaskan faktor purchase intention adalah perceived price dan perceived value. Sementara Manroek (2016) menjelaskan faktor yang mempengaruhi purchase intention adalah brand image, advertising, dan perceived price. 
Menurut Keller (1993) brand image adalah persepsi pelanggan terhadap sebuah brand seperti yang terlihat dari asosiasi brand yang sudah ada di dalam benak pelanggan. Sementara menurut Fianto et al. (2014) brand image secara signifikan mempengaruhi purchase intention. Menurut Kotler (2016) service quality (kualitas pelayanan) adalah setiap tindakan atau kegiatan yang dapat ditawarkan oleh satu pihak kepada pihak lain, pada dasarnya tidak berwujud dan tidak mengakibatkan kepemilikan apapun. Menurut Brady, Szymanski dan Zeithaml (2001) kualitas pelayanan yang baik memiliki dampak positif terhadap purchase intention (minat beli) pelanggan.

Peneliti melihat dengan banyaknya usaha kedai kopi yang tumbuh di Jakarta dengan segmentasi pasar yang luas menjadikan peluang usaha yang menjajikan disertai dengan keunggulan yang diberikan masing-masing kedai kopi. Tujuan penelitian ini adalah untuk mengetahui: (1) pengaruh brand image terhadap purchase intention dan (2) pengaruh service quality terhadap purchase intention. Hasil penelitian di harapkan dapat memberikan informasi kepada kedai kopi dalam pengambilan keputusan mempertahankan serta meningkatkan brand image dan service quality kedai kopi.

\section{LANDASAN TEORI}

Definisi brand image menurut Keller (2013: p.44) "the brand image as a perception about a brand as reflected by the brand associations held in consumer memory." Peneliti mendefinisikan brand image adalah sebagai suatu persepsi dari sebuah produk yang dapat mencerminkan ingatan pelanggan akan produk tersebut. Kotler dan Keller (2016: p.422) mendefinisikan "Any intangible act or performance that one party offers to another that does not result in the ownership of anything". Peneliti mendefinisikan service quality adalah penilaian pelanggan tentang keunggulan menyeluruh terhadap pelayanan yang diterima. Menurut Kotler dan Keller (2016: p.198) "purchase intention is a form of behavior from consumers who wish to buy or choose products based on experience, its use and desire in a product". Peneliti mendefinisikan purchase intention adalah perilaku konsumen terhadap niat pembelian suatu produk atau layanan untuk memenuhi kebutuhan dirinya ataupun orang lain.

Menurut Keller (2000), pengukuran citra merek dapat dilakukan berdasarkan pada aspek sebuah merek, yaitu: mudah diingat, mudah dikenal, dan reputasi merek yang baik. Parasuraman, Berry dan Zeinthaml (2010) dimensi service quality yaitu: Tangible, Reliability, Responsiveness, Assurance, dan Emphaty.

\section{Pengaruh Brand Image terhadap Purchase Intention}

Kurniawan (2012) menemukan bahwa brand loyalty, brand image dan perceived quality mempengaruhi minat beli secara signifikan. Dalam penelitiannya, Wang dan Tsai (2014) menjelaskan bahwa brand image memliki pengaruh positif serta signifikan terhadap purchase intention. Berdasarkan penjelasan diatas, maka hipotesis penelitian sebagai berikut:

H1 : Terdapat pengaruh positif brand image terhadap purchase intention.

\section{Pengaruh Service Quality terhadap Purchase Intention.}

Menurut penelitian Bariroh (2015) terdapat pengaruh yang signifikan dari kualitas pelayanan terhadap minat beli. Semakin tinggi kualitas pelayanan yang diberikan membuat minat peli konsumen semakin tinggi. Kemudian menurut Arslan dan Zaman (2014) menemukan bahwa service quality memiliki dampak positif terhadap minat beli pada retail store di Pakistan. Berdasarkan penjelasan diatas, maka hipotesis penelitian sebagai berikut: $\mathrm{H} 2$ : Terdapat pengaruh positif service quality terhadap purchase intention.

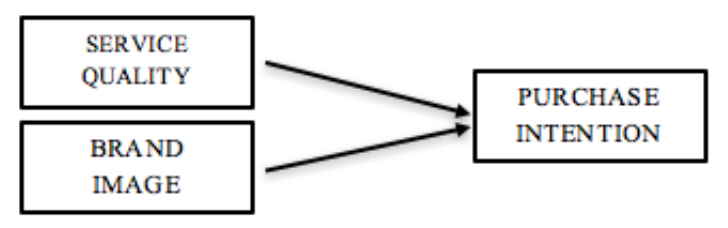




\section{METODOLOGI}

\section{Populasi dan Metode Pengambilan Sampel}

Populasi dalam penelitian ini adalah orang yang pernah membeli produk dari salah satu kedai kopi di Jakarta. Ukuran sampel yang digunakan dalam penelitian ini adalah 150 orang. Metode pengambilan sampel yang digunakan nonprobability sampling dengan teknik convenience sampling. Berdasarkan data yang terkumpul mayoritas karakteristik responden dalam penelitian ini adalah pria (74\%), berusia 31- 40 tahun $(42 \%)$ dengan mayoritas berpendidikan akhir S1 (53\%) yang memiliki pengeluaran perbulan rata-rata di atas Rp. 10.000 .000 per bulan (37\%).

\section{Variabel dan Pengukuran}

Pada penelitian ini, variabel brand image dan service quality merupakan variabel independen, sedangkan purchase intention adalah variabel dependen. Untuk mengukur variabel ini, menggunakan beberapa instrument yang diadaptasi dari studi penelitian terdahulu. Skala pengukuran yang digunakan adalah Skala Likert 5 poin, 1 menunjukan "sangat tidak setuju" dan 5 menunjukan "sangat setuju". Dari hasil uji validitas dan reliabilitas menunjukan bahwa semua variabel yang digunakan dalam penelitian ini adalah valid dan reliabel. Tabel ini dibawah ini menunjukan pengukuran masing - masing variabel dan sumbernya:

Tabel 1

Variabel dan Pengukuran

\begin{tabular}{|c|c|c|}
\hline VARIABEL & ITEM & SUMBER \\
\hline \multicolumn{3}{|r|}{ Variabel Independent } \\
\hline Brand Image & 5 & Lien et al. (2015) \\
\hline \multicolumn{3}{|r|}{ Variabel Independent } \\
\hline Service Quality & 5 & Parasuraman, Berry dan Zeinthaml (2010) \\
\hline \multicolumn{3}{|r|}{ Variabel Dependent } \\
\hline Pruchase Intention & 5 & Busler (2000); Lin dan Lin (2007); Jalilvand et al. (2011) \\
\hline
\end{tabular}

\section{Metode Analisis Data}

Metode analisis data yang digunakan adalah analisis regresi berganda. Sedangkan, untuk uji asumsi klasik seperti uji normalitas, uji heteroskedastisitas, dan multikolinieritas saja. Sedangkan uji otokorelasi tidak dilakukan karena data yang digunakan bersifat cross-sectional dan bukan berbasis waktu (time-series), hasilnya menunjukan uji asumsi sudah terpenuhi. Pengujian dalam penelitian ini menggunakan program SPSS. Taraf signifikansi yang digunakan dalam penelitian ini adalah 0,05. Pengujian untuk analisis data dilakukan dengan pembagian menjadi 2 model yaitu model 1 untuk menguji hipotesis pertama yaitu pengaruh brand image terhadap purchase intention, model 2 untuk menguji hipotesis kedua yaitu untuk pengaruh service quality terhadap purchase intention.

ANALISA DAN PEMBAHASAN

\section{Tabel 2}

Uji Multikolinearitas Brand Image dan Service Quality terhadap Purchase Intention

\begin{tabular}{|l|c|c|c|}
\hline \multicolumn{1}{|c|}{ Variabel } & VIF & Ketentuan & Keterangan \\
\hline Brand Image & 1,868 & VIF $<10$ & Tidak terdapat multikolinearitas \\
\hline Service Quality & 1,868 & VIF $<10$ & Tidak terdapat multikolinearitas \\
\hline
\end{tabular}

Pada tabel di atas peneliti menguji apakah terdapat gejala multikolinearitas pada variabel brand image dan service quality terhadap purchase intention dalam penelitian ini. Dari tabel 
di atas dapat dilihat bahwa nilai VIF dari brand image dan service quality lebih kecil dari 10, maka dapat disimpulkan bahwa tidak terdapat gejala multikolinearitas dari model regeresi tersebut.

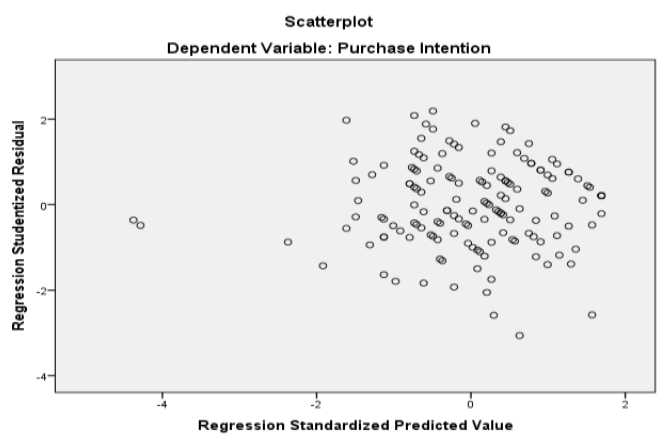

Gambar 1

Scatterplot Brand Image dan Service Quality terhadap Purchase Intention

Pada gambar 4.9 peneliti menguji heterokedasitas brand image dan service quality terhadap purchase intention. Berdasarkan gambar di atas dapat dilihat bahwa titik menyebar di atas dan di bawah angka 0 dari sumbu Y, maka tidak terjadi heterokedasitas.

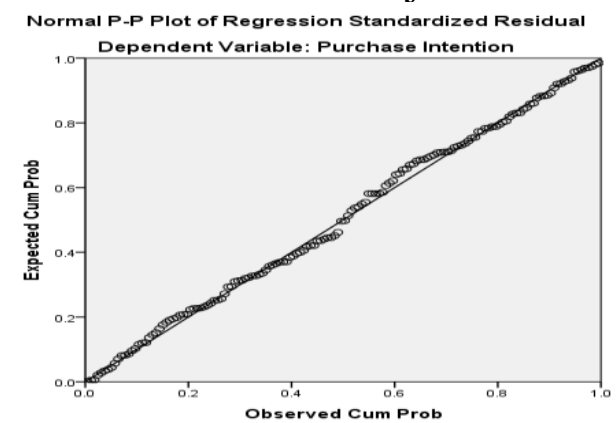

Gambar 2

Uji Normalitas Brand Image dan Service Quality terhadap Purchase Intention

Pada gambar 2 peneliti menguji normalitas pada model penelitian yaitu brand image dan service quality terhadap purchase intention. Berdasarkan hasil uji asumsi normalitas melalui normal probability plot ( $p$-p plot) diketahui bahwa residual data menyebar di sekitar garis diagonal dan mengikuti arah garis diagonal, maka model regresi tersebut memenuhi asumsi normalitas.

Dari hasil analisis secara keseluruhan, disimpulkan bahwa analisis regresi yang dilakukan sudah memenuhi kriteria dan model regresi sederhana maupun ganda dapat digunakan untuk menganalisis data karena sesuai dengan persyaratan, antara lain: 1) Tidak terdapat multikolinearitas, 2) Tidak terdapat heterokedasitas, 3) Residual terdistribusi secara normal.

Tabel 3

Analisis Regresi Ganda Brand Image dan Service Quality terhadap Purchase Intention

\begin{tabular}{|l|r|r|r|r|r|}
\hline \multirow{2}{*}{ Model } & \multicolumn{2}{|c|}{$\begin{array}{c}\text { Unstandardized } \\
\text { Coefficients }\end{array}$} & $\begin{array}{c}\text { Standardized } \\
\text { Coefficients }\end{array}$ & \multirow{2}{*}{ Sig. } \\
\cline { 2 - 4 } & \multicolumn{1}{|c|}{ B } & Std. Error & \multicolumn{1}{c|}{ Beta } & & \\
\hline (Constant) & 1.117 & 1.327 & & .842 & .401 \\
Brand Image & .655 & .072 & .626 & 9.062 & .000 \\
Service Quality & .094 & .030 & .218 & 3.152 & .002 \\
\hline
\end{tabular}

Tabel 3 merupakan hasil regresi dari brand image dan service quality terhadap purchase intention. Berdasarkan tabel di atas, dirumuskan persamaan regresi untuk model penelitian sebagai berikut: PI $=1,117+0,655 \mathrm{BI}+0,094 \mathrm{SQ}$. Dari persamaan di atas dapat disimpulkan bahwa nilai koefisien regresi (B) yang paling besar adalah nilai B pada brand image sebesar 0,655 dan pada service quality sebesar 0,094. 
Tabel 4

Uji-F (ANOVA) Brand Image dan Service Quality Terhadap Purchase Intention

\begin{tabular}{|ll|r|r|r|r|r|}
\hline \multicolumn{1}{|c|}{ Model } & Sum of Squares & \multicolumn{1}{c|}{ df } & Mean Square & F & Sig. \\
\hline 1 & Regression & 1417.394 & 2 & 708.697 & 122.379 & $.000^{\mathrm{b}}$ \\
& Residual & 851.279 & 147 & 5.791 & & \\
& Total & 2268.673 & 149 & & & \\
\hline
\end{tabular}

Dari tabel 4.10 di atas, diperoleh tingkat signifikan sebesar 0,000 dimana menunjukan bahwa angka tersebut lebih kecil dari 0,05. Ini berarti $\mathrm{H}_{0}$ ditolak. Maka dapat disimpulkan bahwa paling sedikit terdapat satu variabel independen yang secara signifikan mempengaruhi purchase intention.

Adapun perumusan hipotesis yang pertama adalah hipotesis ke $1\left(\mathrm{H}_{1}\right)$ terdapat pengaruh positif brand image terhadap purchase intention. Dari tabel 4 dapat disimpulkan bahwa secara parsial variabel brand image mempengaruhi variabel purchase intention secara positif dengan tingkat signifikansi 0,000 lebih kecil dari $\alpha=0,05$, maka dapat disimpulkan $\mathrm{H}_{1}$ tidak ditolak.

Hipotesis yang kedua $\left(\mathrm{H}_{2}\right)$ adalah Terdapat pengaruh positif service quality terhadap purchase intention. Dari tabel 4 dapat disimpulkan bahwa secara parsial variabel service quality mempengaruhi variabel purchase intention secara positif dengan tingkat signifikansi 0,000 lebih kecil dari $\alpha=0,05$, maka dapat disimpulkan $\mathrm{H}_{1}$ tidak ditolak.

\section{PENUTUP}

\section{Kesimpulan}

Berdasarkan hasil penelitian analisis yang dilakukan, maka dapat disimpulkan sebagai berikut: 1) Terdapat pengaruh positif brand image dan signifikan terhadap purchase intention, 2) Terdapat pengaruh positif service quality dan signifikan terhadap purchase intention.

\section{Saran}

Peneliti menyarankan perusahaan dapat memperhatikan faktor-faktor brand image agar dapat meningkatkan citra merek dimata konsumennya. Hal ini dapat dilakukan dengan melakukan inovasi dalam produk minuman kopi misalnya, serta inovasi terhadap (tumbler) dengan variasi ukuran yang lebih banyak lagi. Perusahaan juga dapat meningkatkan service quality dengan memberikan pengarahan kepada pramusaji agar dapar meniciptakan suasana santai tapi tetap menghormati konsumen. Perusahaan juga dapat memberikan arahan kepada setiap barista agar lebih komunikatif terhadap konsumen agar tercipta komunikasi dua arah untuk mendapatkan produk minuman sesuai dengan keinginan konsumen. Kemudian perusahaan dapat melakukan inovasi-inovasi terhadap ambience and service place yang dimiliki kedai-kedai sehiangga konsumen dapat mempromosikan perusahaan sebagai tempat yang nyaman dan elegan.

\section{DAFTAR PUSTAKA}

Arslan, M., \& Zaman, R. (2014). Impact of Corporate Social Responsibility on Brand Image: A Study on Telecom Brands. 4 (21), 84-90. Retrieved from

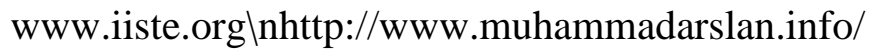

Bariroh, Hikmatul. (2015). Pengaruh Kualitas Pelayanan terhadap Minat Membeli Konsumen pada Minimarket Indomart dan Minimarket Alfamart. Undergraduate Thesis, Universitas Islam Negeri Maulana Malik Ibrahim Malang.

Brady, M.K. \& Cronin, J.J. (2001). Some New Thoughts on Conceptualizing Perceived Service Quality: A Hierarchical Approach. The Journal of Marketing 2001, 65 (3), 34-49.

Fianto, A.Y.A., Hadiwidjojo D., \& Aisijah Siti, Malang (2014). The Influence of Brand Image of Purchase Behaviour Through Brand Trust. Journal of Business Management and Strategy, 5 (2), 58-76.

Keller, K. L. (1993). Conceptualizing, Measuring, Managing Customer-Based Brand Equity. Journal of Marketing, 57 (1), 1-22. 
Keller, K.L. (2013). Strategic Brand Management : Building, Measuring, Managing Brand Equity ( ${ }^{\text {th }}$ ed.). Global Edition : Pearson.

Keller, Kevin Lane. (2000). Strategic Brand Management : Building, Measuring, and Managing Brand Equity. New Jersey : Prentice Hall.

Kotler, Philip \& Keller, K.L. (2016). Marketing Management $\left(15^{\text {th }}\right.$ ed.). New Jersey : Pretience Hall.

Kurniawan, S. D. (2012). Analisis Pengaruh Brand Loyalty, Brand Image, Iklan, dan Perceived Quality terhadap Minat Beli Konsumen XL Prabayar di Kota Surabaya.

Manroek, S.L. (2016). The Influence of Brand Image, Advertising, Perceived Price Toward Consumer Purchase Intention (Case Study: Samsung Smartphone). Jurnal Berkala Ilmiah Efisiensi, 16 (1), 661-670

Oosthuizen, D., Spowart, J., \& De Meyer-Heydenrych, C. (2015). The Relationship Between Perceived Price and Consumers" Purchase Intentions of Private Label Wine Brands. African Journal of Hospitality, Tourism and Leisure, 4 (2), 1-17.

Parasuraman, A., Zeithaml, V.A. \& Berry, L.L. (1998). SERVQUAL: A Multiple Item Scale for Measuring Consumer Perceptions of Service Quality. Journal of Retaling, 64 (1), 1240.

Wang, Y. H. \& Tsai, C. F. (2014). The Relationship between Brand Image and Purchase Intention: Evidence from Award Winning Mutual Funds. The International Journal of Business and Finance Research, 8 (2).

Zeithaml, V.A. (1998). Consumer Perceptions of Price, Quality, and Value: A Meansend Model and Shynthesis of Evidence. Journal of Marketing, 52 (3), 2-22. 